\title{
The effect of circular holes on the natural frequencies of a beam using transverse vibration measurements method
}

\author{
Tariq Khalid Abdilrazzaq \\ Technical college-Mosul
}

\begin{abstract}
Defects influence in a negative way the service life of the structures. Thus, defect detection has been a considerable effort in order to eliminate this effect. In this study, the dynamical behavior of a cantilever beam, with different size of a hole, at different distances from the fixed end-for each case- have been measured, evaluated and compared with that of intact beam. It has been shown that the hole may be considered as a defect in most cases, which leads-in general- to decrease the stiffness, according to its size and place, hence affects the dynamic properties i.e., the natural frequencies and the mode shapes. A simulation process for the modal analysis using ANSYS program(release 12.1) is done in order to compare the results. In addition to that, a theoretical analysis is also done. The experimental results of the intact beam were compared with both the ANSYS program and the theoretical results. They showed an acceptable agreement between the three methods.
\end{abstract}

Keywords: transverse vibration, fault detection, beam crack, beam defect, beam vibration.
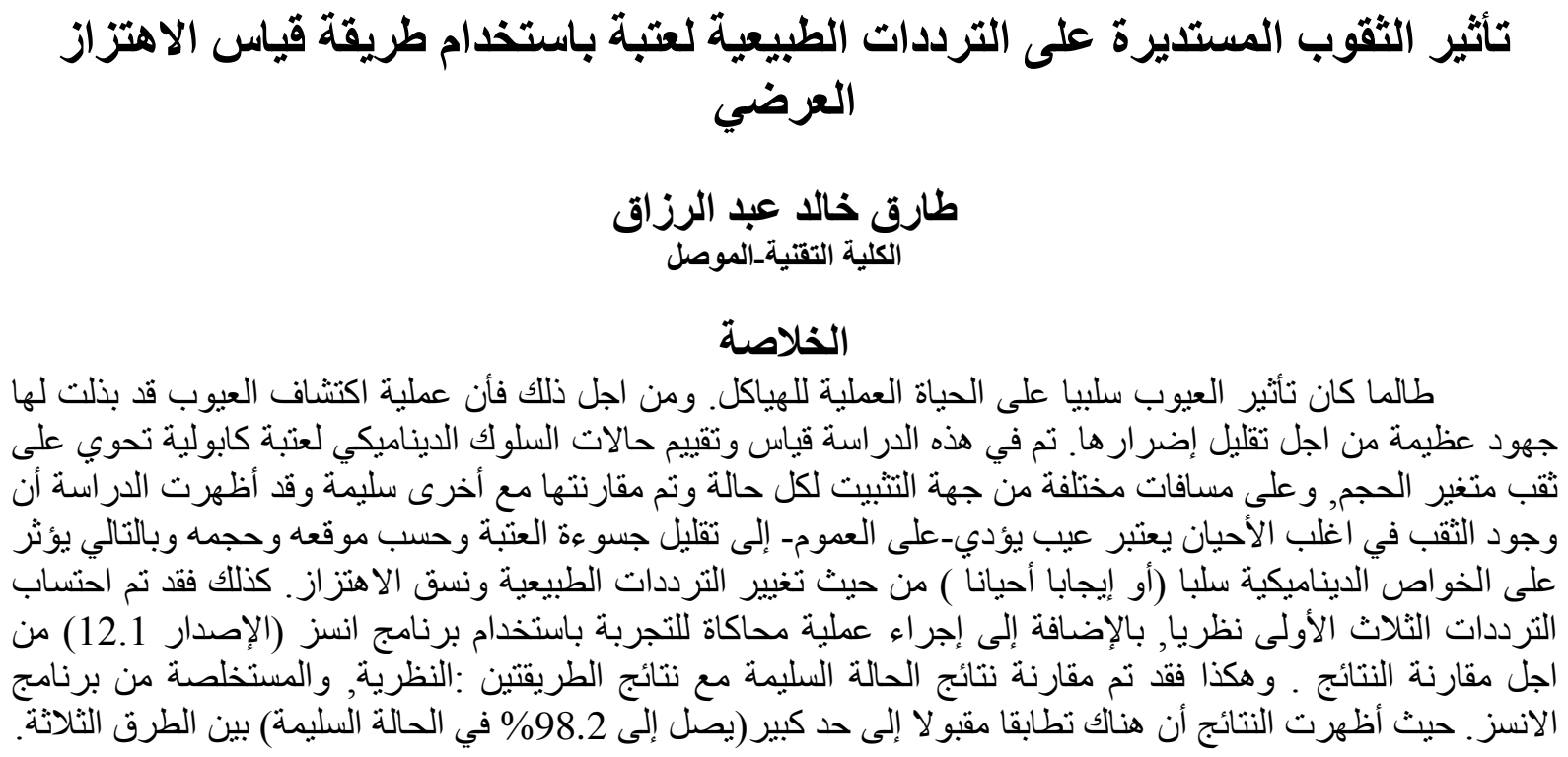


\section{Introduction}

Defects may lead to under designed structures in many cases and increase the vulnerability of structures to static and dynamic loads. Although most of these deficient structures are not likely to collapse, they must be limited to designated ultimate loads that should be determined based on the properties of the damaged structure [1]. Literature on fault detection and condition monitoring was focused on the vibration-based method which can be classified into modal-based and signature-based methods. In modal based techniques data can be condensed from the actual measured quantities like resonant frequencies, mode shape vectors and quantities derived from these parameters for the crack detection [2]. In signature based methods the vibration signature of cracked machinery structure can be useful for the fault diagnosis and condition monitoring. Thus, the development of crack detection methods has received increasing attention in recent years. Among these techniques, it is believed that the monitoring of the global dynamics of a structure offers favorable alternative if the on-line (in service) damage detection is necessary. In order to identify structural damage by vibration monitoring, the study of the changes of the structural dynamic behavior due to cracks is required for developing the detection criterion [3]. Many investigators have studied the effect of defects and cracks in different vibrating structures. Columns and beams are used in many machines and structures in engineering, cracks in these parts can not only cause a decrease in the critical loading of the part, but causes vibration response problems as well [4-7]. Cracks or other defects in a structural element influence its dynamical behavior and change its stiffness and damping properties. Consequently, the natural frequencies and mode shapes of the structure contain information about the location and dimensions of the damage. Vibration analysis, which can be used to detect structural defects such as cracks, of any structure offers an effective, inexpensive and fast means of nondestructive testing. Patil and Maiti [8] experimentally verified a method for prediction the location and size of multiple cracks based on measurement of natural frequencies of slender multi-cracked cantilever beams. Kisa [9] investigated the effects of cracks on the dynamical characteristics of a cantilever composite beam, made of graphite fiber-reinforced polyamide with multiple cracks. Kisa \& Gurel [10] proposed a numerical model that combines the finite element and component mode synthesis methods for the modal analysis of beams with circular cross section and containing multiple non-propagating open cracks. Ruotolo and Surace [11] presented a damage assessment of multiple cracked beams using the modal parameters of the lower modes. Zheng and Fan [12] analyzed free vibration of a non-uniform beam with multiple cracks by using a kind of modified Fourier series. Chatin et al.[13] investigate the modal analysis of a cantilever beam with a transverse edge crack. Pugno et al.[14] presented a technique capable of evaluating the dynamic response of a beam with several breathing cracks perpendicular to its axis and subjected to harmonic excitation. excitation. The method described is based on the assumption of periodic response and cracks open and close continuously. Collins et al. [15] used a direct numerical integration to study forced vibrations of a beam with breathing crack. Resonance frequency shifts the power spectrum due to defects in a longitudinally vibrating beam when both ends are free investigated by Sobue et al. [16] both numerical and experimental analysis. Calculation using a transfer matrix method showed that the frequency shift was large when the defect position coincides with a node of vibration. A semi-analytical approach for the Eigen problem of circular plates with multiple circular holes is Presented by Lee \& Chen[17] . Natural frequencies and modes are determined. The effect of eccentricity of the hole on the natural frequency and mode shape is also considered. 


\section{Theory}

When a crack or defect exists in a beam or shaft, then the stiffness is reduced and consequently the Eigen frequencies of the system are decreased. Measuring these differences can help to identify a crack. $[18,19]$.

Consider the forces and moments acting on an element of a beam shown in Fig.1. Let $\mathrm{Q}$ and $\mathrm{M}$ be the shear and bending moment respectively, and $\mathrm{w}(\mathrm{x})$ represents the loading per unit length of the beam. By summing forces in the y-direction, we have:

$$
\left[Q+\frac{\partial Q}{\partial x} \mathbf{d x}\right]-\mathbf{Q}=\mathbf{w}(\mathbf{x}) \mathrm{dx}
$$

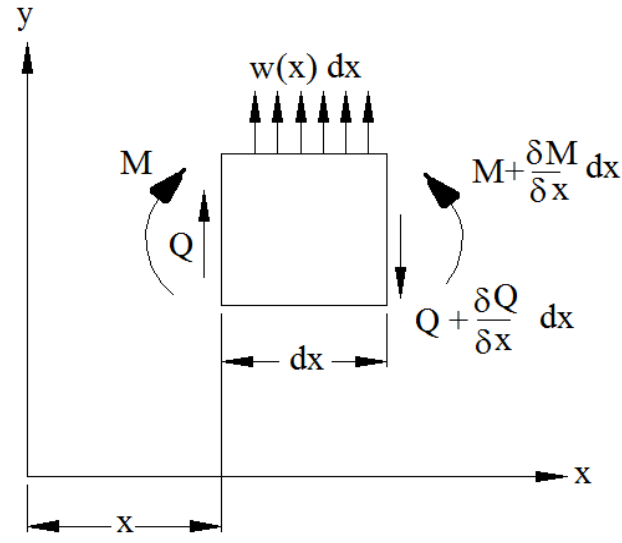

Fig. 1 Lateral vibration of beam

Or

$\frac{\partial Q}{\partial x}=\mathbf{w}(\mathbf{x})$

Taking moments about any point on the right end of the element, we get:

$\mathbf{Q} \mathbf{d x}+\mathbf{w}(\mathbf{x}) \mathbf{d x} \cdot \frac{d x}{2}-\left[\mathbf{M}+\frac{\partial M}{\partial x} \mathbf{d x}\right]+\mathbf{M}=\mathbf{0}$

Ignoring small quantities, we get

$\mathbf{Q}=\frac{\partial M}{\partial x}$

From Eqs. (1) and (2), we get

$\mathbf{w}(\mathbf{x})=\frac{\partial^{2} M}{\partial x^{2}}$

Now $\quad \mathbf{E I} \frac{d^{2} y}{d x^{2}}=\mathbf{M}$

Or $\quad \frac{\partial^{2}}{\partial x^{2}}\left[\mathrm{EI} \frac{\partial^{4} y}{\partial x^{4}}\right]=\mathbf{w}(\mathbf{x})$

Where $E=$ modulus of elasticity $(\mathrm{N} / \mathrm{m} 2)$, and $\mathrm{I}=$ area moment of inertia $(\mathrm{m} 4)$.

$\mathrm{I}=\frac{b h^{3}}{12}$.

Let $\rho=$ density of beam material in $\mathrm{kg} / \mathrm{m}^{3}$

$\mathrm{A}=$ cross-sectional area of beam. in $\mathrm{m}^{2}$

Assuming harmonic motion, we have

$$
\begin{aligned}
& \mathrm{w}(\mathrm{x})=\rho \mathrm{A} \omega^{2} y \\
& \text { or } \quad \mathrm{EI} \frac{\partial^{4} y}{\partial x^{4}}-\rho \mathrm{A} \omega^{2} \mathrm{y}=0
\end{aligned}
$$

where = natural frequency of the mode $(\mathrm{rad} / \mathrm{sec})$,

Let $\boldsymbol{\beta}^{4}=\rho \mathrm{A} \omega^{2} / \mathbf{E I}$, then

$\frac{\partial^{4} y}{\partial x^{4}}-\beta^{4} y=0$

The general solution of Eq.(6) is

$y=A \cosh \beta x+B \sinh \beta x+C \cos \beta x+D \sin \beta x$

$\omega_{\mathrm{n}}=\beta_{\mathrm{n}}{ }^{2} \sqrt{\frac{E I}{\rho A}}$

$\omega_{\mathrm{n}}=\left(\boldsymbol{\beta}_{\mathrm{n}} \mathrm{L}\right)^{2} \sqrt{\frac{E I}{\rho A L^{4}}}$

The values of $\left(\boldsymbol{\beta}_{\mathbf{n}} \mathbf{L}\right)^{\mathbf{2}}$ for the three first modes are given in table (1) for the lateral vibrations of a cantilever [20-22]. 
Table (1) Numerical values of $\left(\beta_{n} L\right)^{2}$ for typical end conditions

\begin{tabular}{|l|l|l|l|}
\hline \multirow{2}{*}{$\begin{array}{l}\text { Beam } \\
\text { configuration }\end{array}$} & $\left(\beta_{\mathrm{n}} \mathrm{L}\right)^{2}$ & $\left(\beta_{\mathrm{n}} \mathrm{L}\right)^{2}$ & $\left(\beta_{\mathrm{n}} \mathrm{L}\right)^{2}$ \\
\cline { 2 - 4 } Sundamental mode & Second mode & Third mode \\
\hline Simply supported & 9.87 & 39.5 & 88.9 \\
\hline Cantilever & 3.52 & 22.0 & 61.7 \\
\hline Free-Free & 22.4 & 61.7 & 121.0 \\
\hline Clamped-Clamped & 22.4 & 61.7 & 121.0 \\
\hline Clamped-Hinged & 15.4 & 50.0 & 104.0 \\
\hline Hinged-Free & 0 & 15.4 & 50.0 \\
\hline
\end{tabular}

\section{Experimentation}

Experiments were carried out on a cantilever beam medium carbon steel with modulus of elasticity $=206 \times 10^{9} \mathrm{~N} / \mathrm{m}^{2}$ with dimensions of (length $\mathrm{L}=0.5 \mathrm{~m}$, width $\mathrm{w}=4 \mathrm{~cm}$, and the height $h=0.5 \mathrm{~cm}$ ) as in Fig. 2.
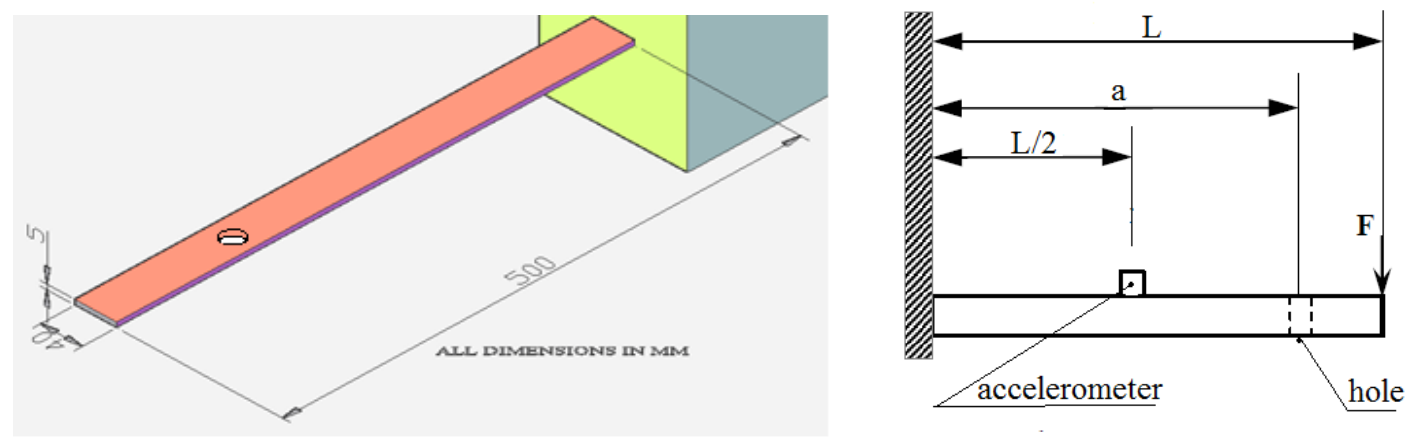

Fig. 2 cantilever beam with hole

The beam was pulled to a distance according to the load that attached with a rope to the free end of the beam, then the rope is released to vibrate the beam in order to keep a constant excitation for all the cases in the study which affects on the amplitude of vibration. The schematic representation of the model, procedure and the components of this experimentation can be shown in Fig. 3.

Vibration signals were collected for both the intact and the defected beam conditions. With the accelerometer mounted on the beam at the middle,

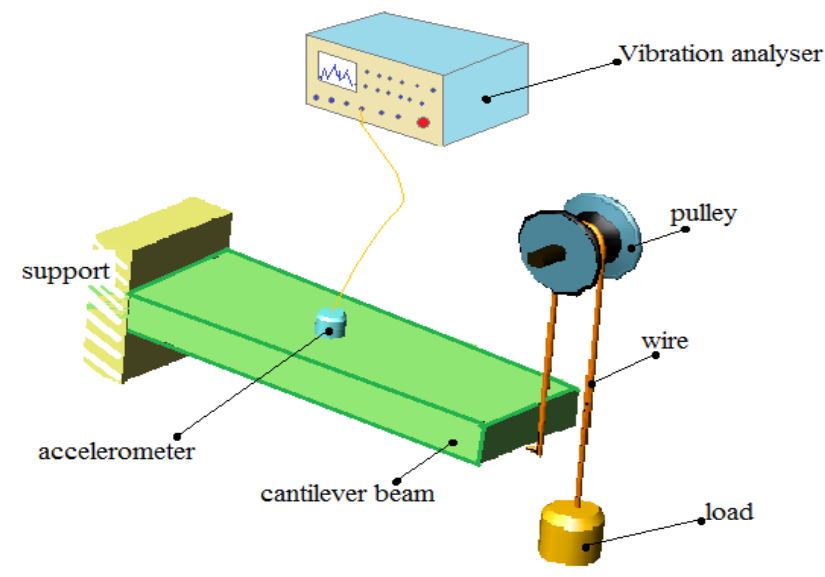

Fig.3 Schematic representation of the model and procedure Fig.4.

vibration signals were measured for various fault conditions when beam was excited, then left to vibrate without any excitation as a free vibration case, using Schenck - vibroport- 30 portable field vibration analyzer in order to get the Fast Fourier Transformat ion to transfer the vibration from the time domain to the frequency domain . 


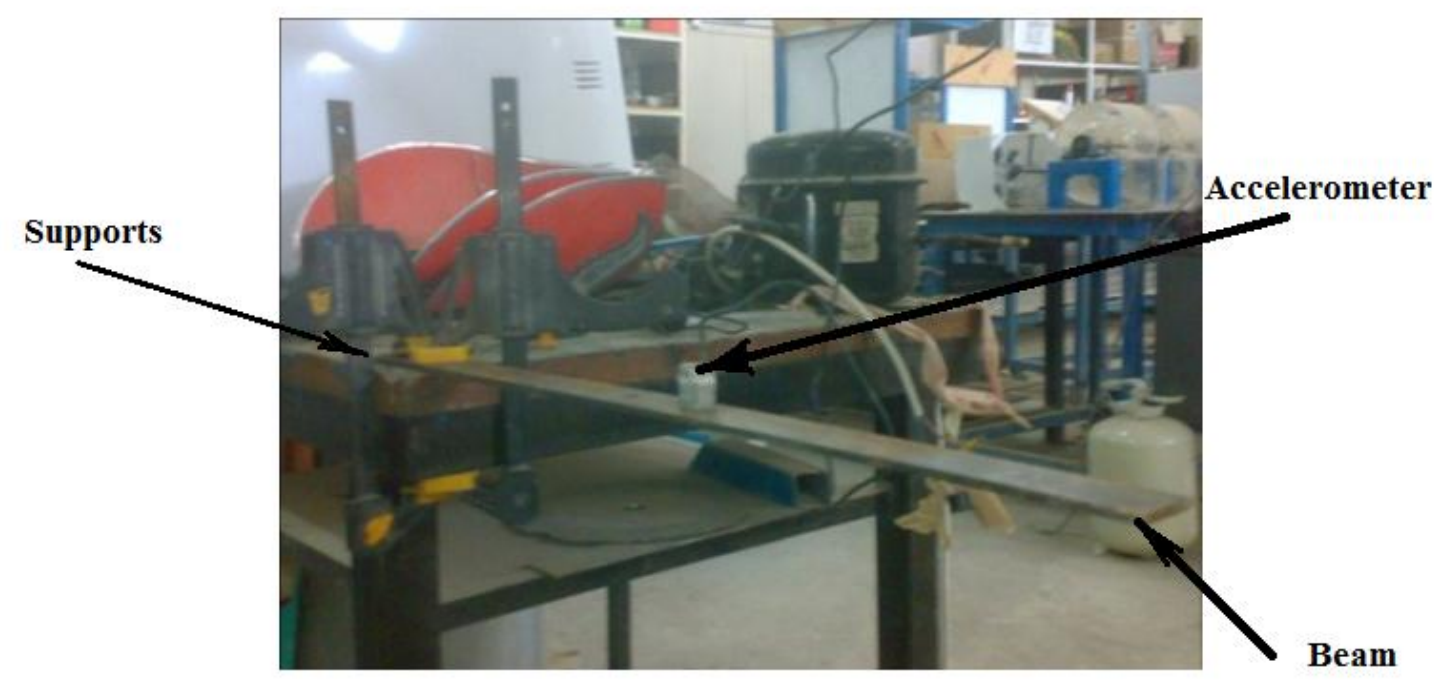

Fig.4 Measuring the beam vibration

The vibration signals were measured, analyzed for the intact beam, the natural frequencies can be specified from spectrum analysis, as shown in Fig. 5 then a hole of $8 \mathrm{~mm}$ diameter is made on the beam at a distance $a=375 \mathrm{~mm}$ from the fixed end (i.e. $\mathbf{a}=\mathbf{0 . 7 5} \mathbf{L}$ ). The vibration signals were measured and analyzed for this case and for other two cases, in which the hole was enlarged to be $12 \mathrm{~mm}$ diameter and $16 \mathrm{~mm}$ diameter consequently. A similar two other specimens are measured with holes of the same sizes $(\mathbf{8}, \mathbf{1 2}$, and $\mathbf{1 6 m m})$ but one at a distance of $250 \mathrm{~mm}$ (i.e. $\mathbf{a}=\mathbf{0 . 5} \mathbf{L}$ ), and the other at a distance of $125 \mathrm{~mm}$ (i.e. $\mathbf{a}=\mathbf{0 . 2 5} \mathbf{L}$ ) . Fig. 6 shows the three beams with locations of the holes.

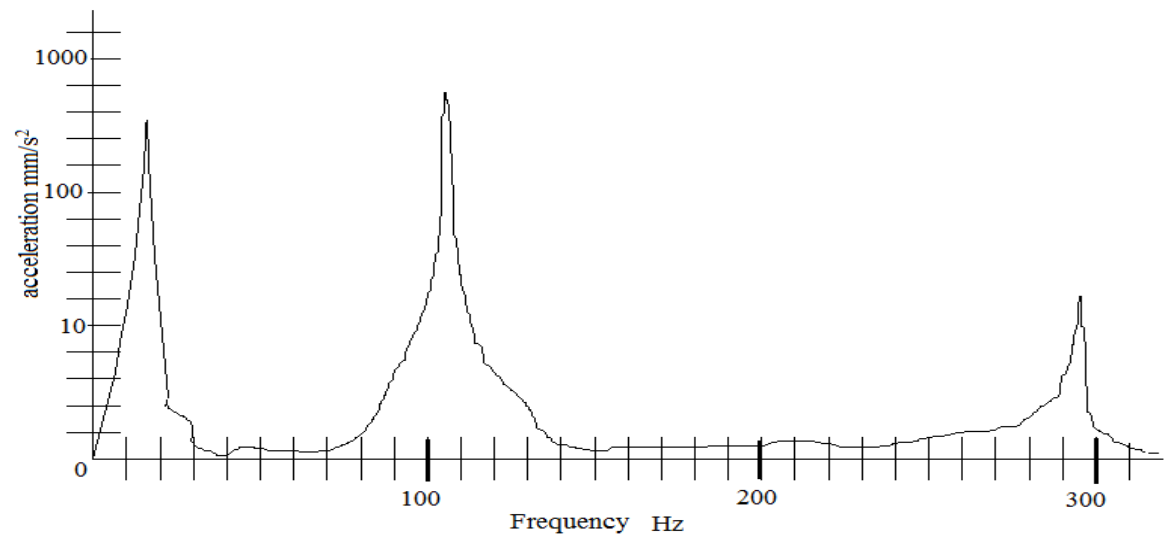

Fig. 5 Spectrum analysis for the Intact case
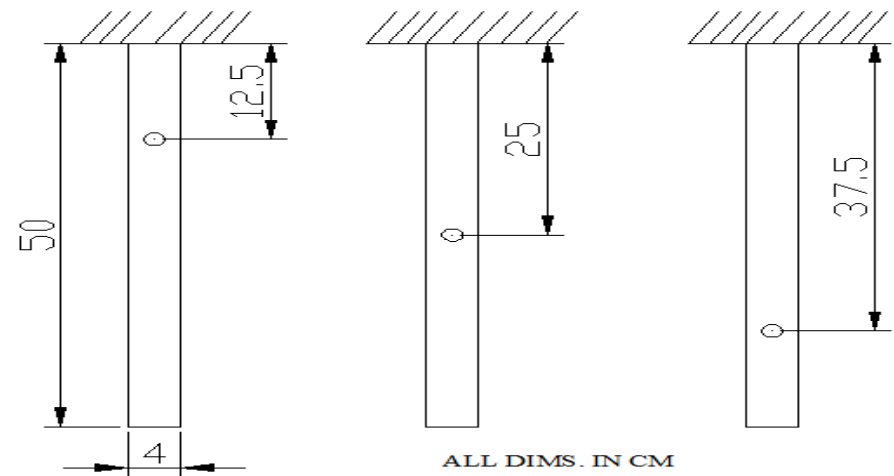

Fig. 6 The three beams with the locations of the holes 


\section{Discussion}

In order to show the acceptance between the three methods (Experimental, theoretical, and ANSYS program), The natural frequencies for the intact case were listed in table 2 and plotted in Fig. 7. where F1, F2, and F3 are the First, Second and Third natural frequencies consequently. The measurements, analytical, and ANSYS methods have taken as a torsional uncoupled vibration case. It can be shown that there is a good acceptance between the three methods.

Table (2) Theoretical and experimental values of the first three natural frequencies (intact case)

\begin{tabular}{|l|l|l|l|}
\hline & F1 $(\mathrm{Hz})$ & F2 $(\mathrm{Hz})$ & F3 $(\mathrm{Hz})$ \\
\hline Theoretical & 16.55 & 103.5 & 290 \\
\hline Experimental & 16.5 & 105 & 295 \\
\hline Ansys 12.1 & 16.701 & 104.625 & 293.224 \\
\hline
\end{tabular}

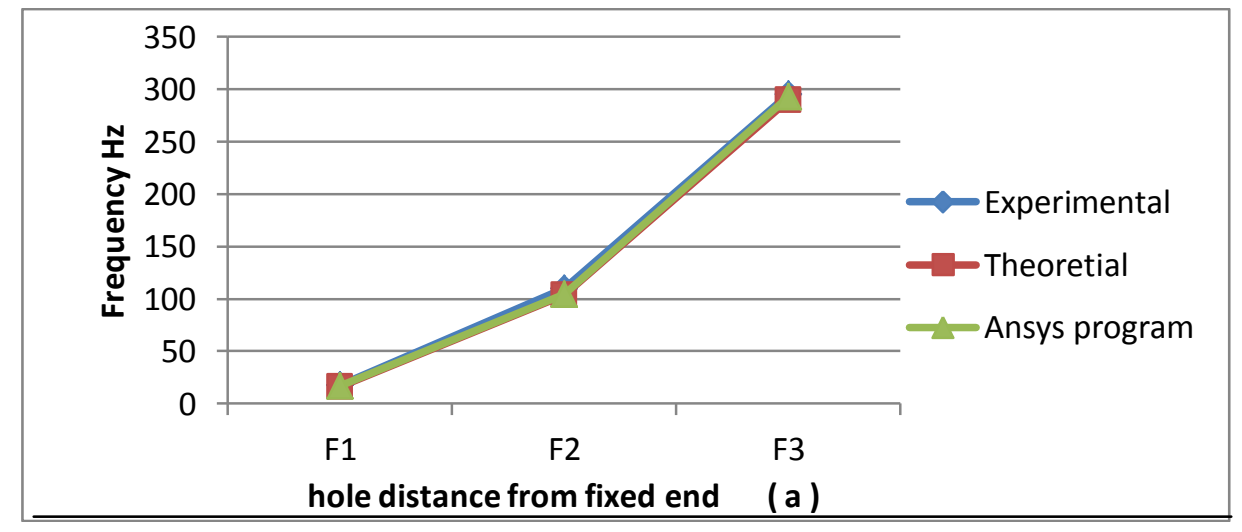

Fig. 7 The three Natural Frequencies for intact cantilever beam

The cases of different hole sizes at different distances are plotted. They are compared in order to observe the changes in natural frequencies. For the fundamental natural frequency( F1), the influence were shown obviously in Fig. 8 which reveals that the natural frequency decreased when the location of the hole is closer to the fixed end (i.e. smaller a) .Fig. 9 shows the effect of the hole size on the natural frequency, as the hole size increases, its location will be more effective to decrease the natural frequency of the short distance $(a=0.25 \mathrm{~L})$ and vice versa. The mode shape for the fundamental natural frequency can be shown in Fig 10. For the second harmonic frequency," Fig. 11", it can be shown that the natural frequency was decreased as the location distance increased, the effect of hole size on the second harmonic frequency can be shown at the middle of the beam (i.e. $a=0.5 \mathrm{~L}$ ), when the hole size increases, the natural frequency decreases, this can be attributed to the mode shape of the second harmonic Fig.13 the big hole is at the peak point leads to weaken the beam . For the third harmonic frequency Fig.14, it can be shown that that natural frequency decreases with the increase of the hole distance from the fixed end, the effect of the hole size can be shown in Fig. 15, when the hole is at $0.75 \mathrm{~L}$, the natural frequency decreases as the hole size increases, which may attributed again to the mode shape and the location of the hole near the peak point (i.e. maximum amplitude). The mode shape of the third harmonic frequency can be shown in Fig. 16. 


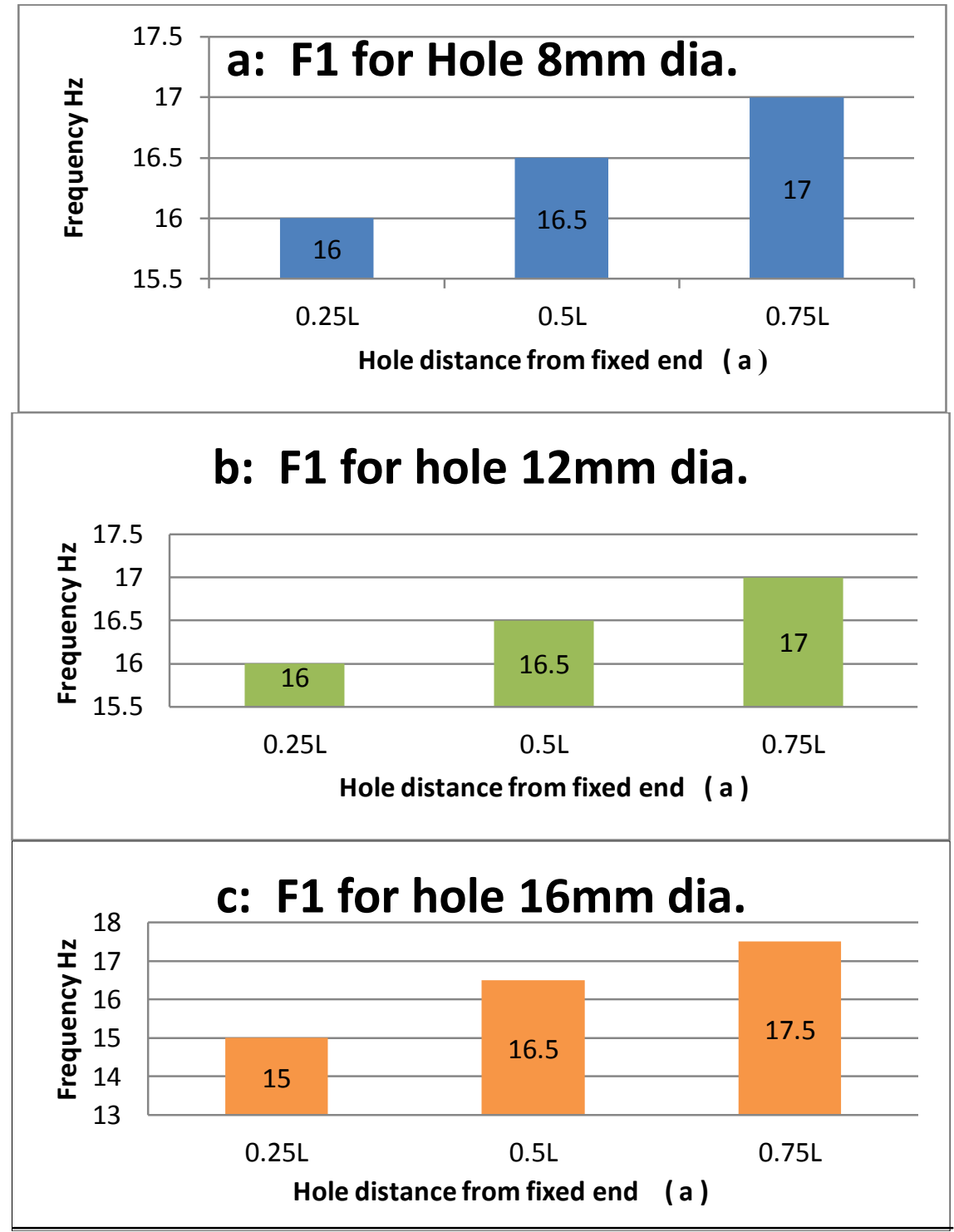

Fig. 8 Effect of hole location on Fundamental natural frequency F1

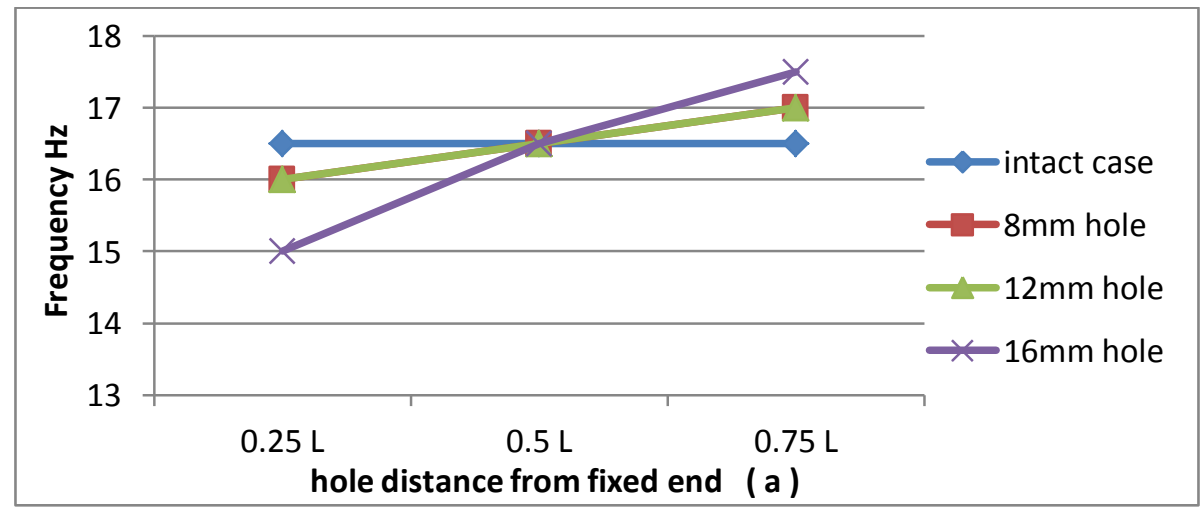

Fig. 9 Fundamental Natural Frequency (F1) 


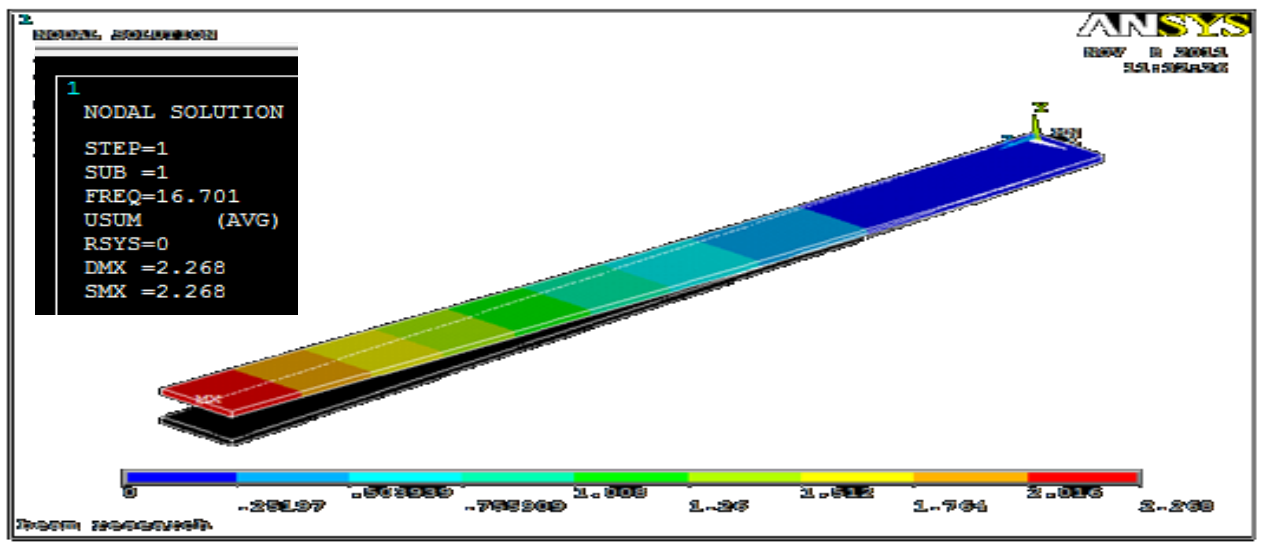

Fig. 10 Fundamental natural frequency and mode shape using ANSYS 12.1 program

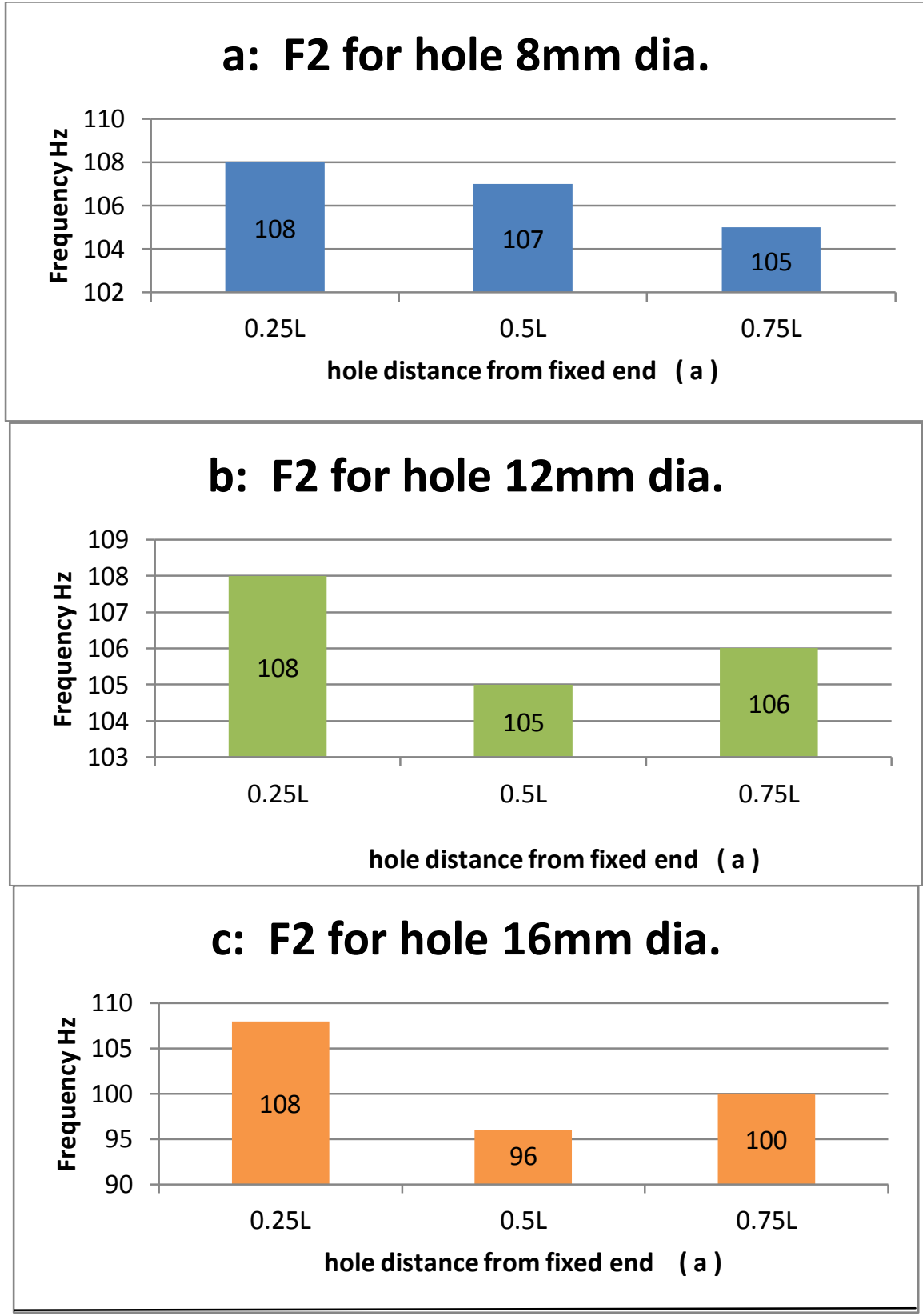

Fig. 11 Effect of hole location on the Second natural frequency F2 


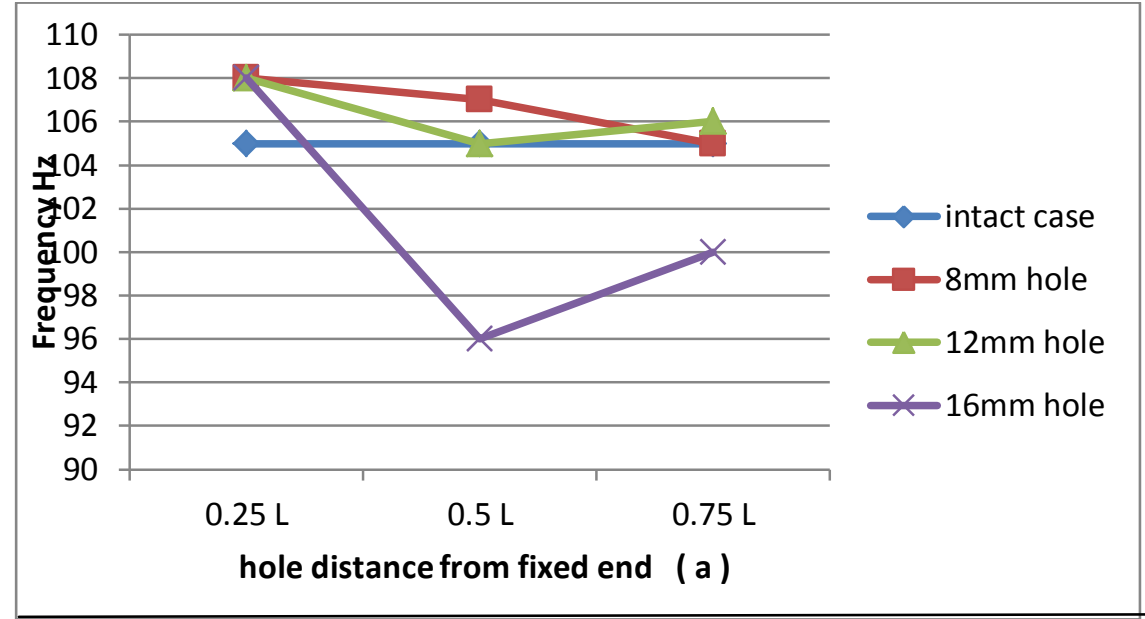

Fig. 12 Second harmonic frequency

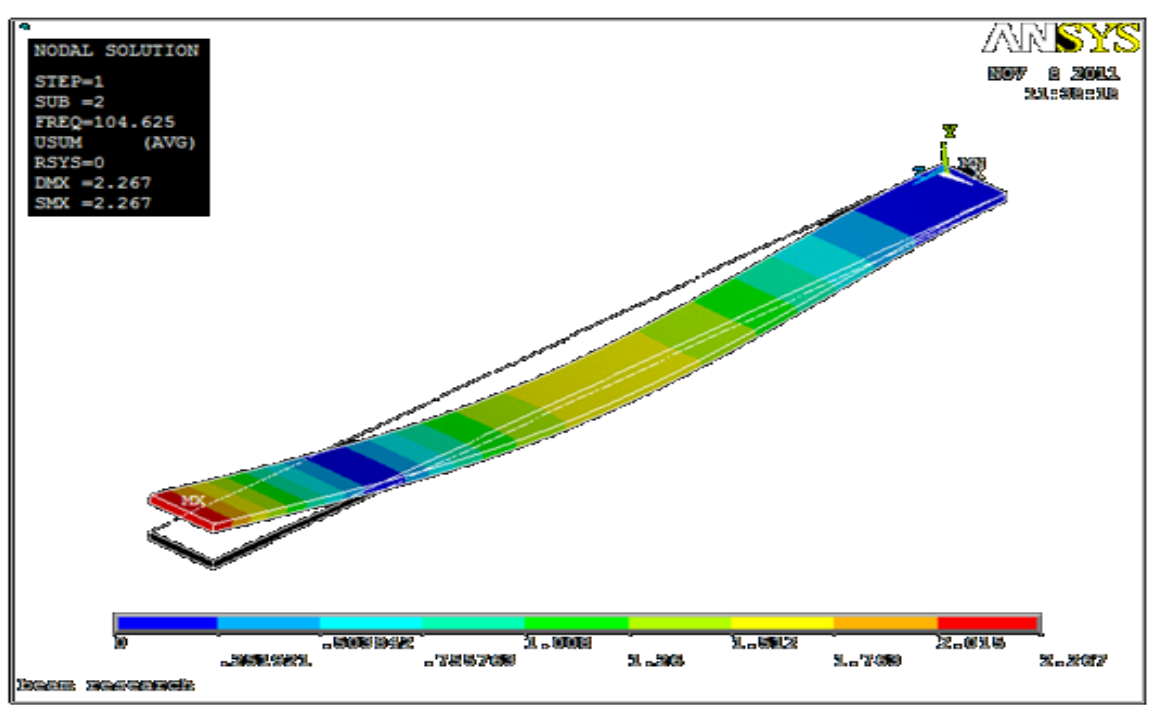

Fig. 13 Second harmonic frequency using ANSYS 12.1 program

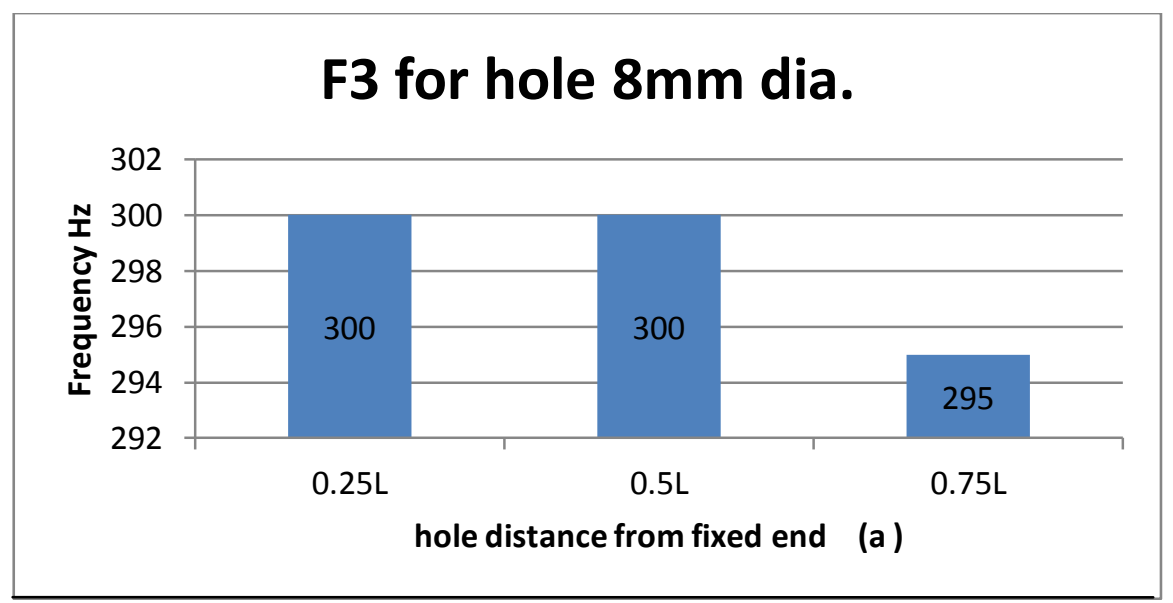




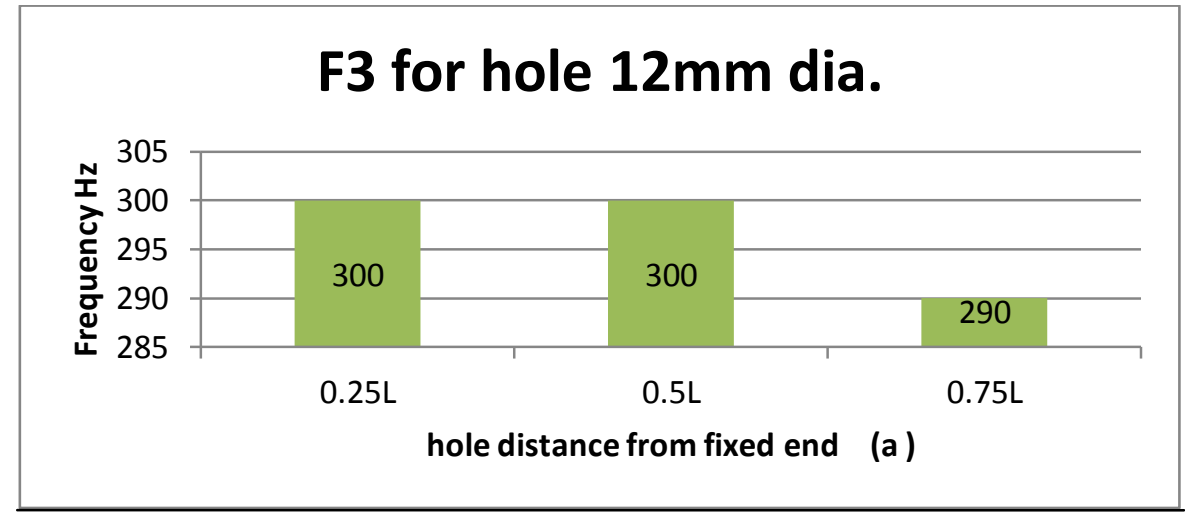

Fig. 14 Effect of hole location on the Third natural frequency F3

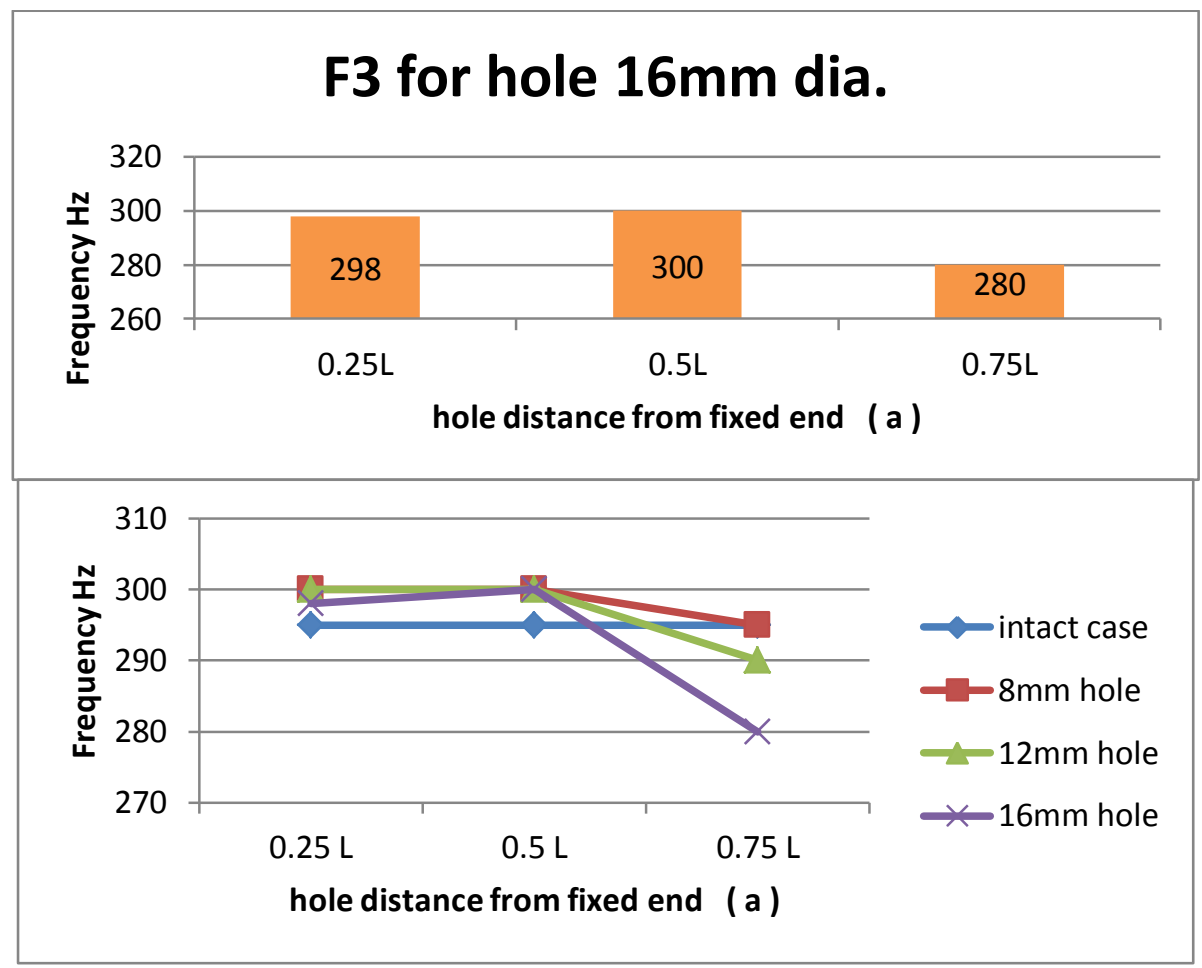

Fig. 15 Third harmonic frequency

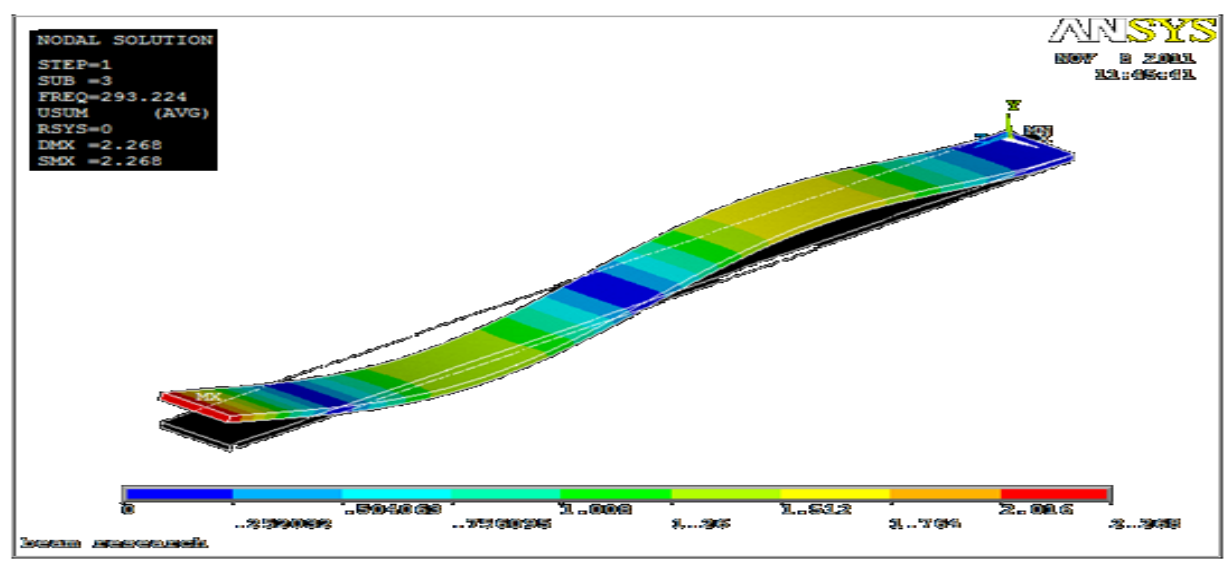

Fig. 16 Third harmonic frequency using ANSYS 12.1 program 
Data for the cases shown above can be shown in tables 3,4, and 5 below.

Table (3) Natural frequencies for the cantilever with a $8 \mathrm{~mm}$ hole at a three different places (a)

\begin{tabular}{|c|c|c|c|}
\hline $\mathrm{a}(\mathrm{mm})$ & $\mathrm{F} 1(\mathrm{~Hz})$ & $\mathrm{F} 2(\mathrm{~Hz})$ & $\mathrm{F} 3(\mathrm{~Hz})$ \\
\hline $0.25 \mathrm{~L}=125$ & 16 & 108 & 300 \\
\hline $0.5 \mathrm{~L}=250$ & 16.5 & 107 & 300 \\
\hline $0.75 \mathrm{~L}=375$ & 17 & 105 & 295 \\
\hline
\end{tabular}

Table (4) Natural frequencies for the cantilever with a $12 \mathrm{~mm}$ hole

\begin{tabular}{|c|c|c|c|}
\hline $\mathrm{a}(\mathrm{mm})$ & $\mathrm{F} 1(\mathrm{~Hz})$ & $\mathrm{F} 2(\mathrm{~Hz})$ & $\mathrm{F} 3(\mathrm{~Hz})$ \\
\hline $0.25 \mathrm{~L}=125$ & 16 & 108 & 300 \\
\hline $0.5 \mathrm{~L}=250$ & 16.5 & 105 & 300 \\
\hline $0.75 \mathrm{~L}=375$ & 17 & 106 & 290 \\
\hline
\end{tabular}

Table (5 ) Natural frequencies for the cantilever with a 16mm hole

\begin{tabular}{|c|c|c|c|}
\hline $\mathrm{a}(\mathrm{mm})$ & $\mathrm{F} 1(\mathrm{~Hz})$ & $\mathrm{F} 2(\mathrm{~Hz})$ & $\mathrm{F} 3(\mathrm{~Hz})$ \\
\hline $0.25 \mathrm{~L}=125$ & 15 & 108 & 298 \\
\hline $0.5 \mathrm{~L}=250$ & 16.5 & 96 & 300 \\
\hline $0.75 \mathrm{~L}=375$ & 17.5 & 100 & 280 \\
\hline
\end{tabular}

\section{Conclusions}

It can be observed from the experimental and numerical results that holes may be considered as defects which affect the dynamic characteristics of the beam depending on their sizes and locations, the three first natural frequencies may shifted. The fundamental natural frequency increases as the size of the hole and its location distance from the fixed end increase. The location of a comparatively large size hole in the middle of the beam length decreases the second harmonic frequency, this may attributed to the mode shape, as the hole is located at a place of maximum amplitude, i.e. the place where the beam bends there. The third harmonic frequency decreases as the size of the hole and its location distance from the fixed end increase.

\section{References}

[1] T. Yan - J. Yang - S. Kitipornchai. " Nonlinear dynamic response of an edge-cracked functionally graded Timoshenko beam under parametric excitation ". Nonlinear Dynamics (2012) 67:527-540.

[2] T.G.Chondros, A.D. Dimarogonas and J. Yao, "A Continuous cracked beam vibration theory.", Journal of Sound and Vibration, 215(1), (1998), pp.17-34.

[3] George D. Gounaris, Chris A. Papadopoulos, "Crack identification in rotating shafts by coupled response measurements.", Engineering Fracture Mechanics, 69, (2002), pp.339-352.

[4] Brad A. Butrym, "Crack detection in aluminum structures.", Master thesis Virginia Polytechnic Institute and State University, USA, (2010).

[5] G.M. Owolabi, A.S.J. Swamidas*, R. Seshadri." Crack detection in beams using changes in frequencies and amplitudes of frequency response functions". Journal of Sound and Vibration 265 (2003) 1-22. 
[6] Yue Cheng a,b,n, ZhigangYu b, XunWub, YuhuaYuan b." Vibration analysis of a cracked rotating tapered beam using the p-version finite element method". Finite Elements in Analysis and Design 47 (2011) 825-834.

[7] Mogal Shyam Prabhakar." Vibration Analysis of Cracked Beam" . master thesis Machine Design and Analysis Department of Mechanical Engineering National Institute of Technology Rourkela, India, (2009).

[8] Patil DP, Maiti SK., "Experimental verification of a method of detection of multiple cracks in beams based on frequency measurements.", Journal of Sound and Vibration (2005); 281:439-51.

[9] Murat Kisa," Free vibration analysis of a cantilever composite beam with multiple cracks.", Composites Science and Technology 64 (2004) 1391-1402

[10] Murat Kisa, \& M. Arif Gurel," Modal analysis of multi-cracked beams with circular cross section.", Engineering Fracture Mechanics 73 (2006) 963-977.

[11] Ruotolo R, Surace C., "Damage assessment of multiple cracked beams: numerical results and experimental validation.", Journal of Sound and Vibration (1997);206:567-88.

[12] Zheng DY, Fan SC. "Natural frequencies of a non-uniform beam with multiple cracks via modified Fourier series.", Journal of Sound and Vibration , (2001); 242:701-17.

[13] Chatin," Modal Analysis of a cracked beam.", Journal of Sound and Vibration (1997) 207(2), 249-270.

[14] Nicole Pugno, Cecilia Surace, Romualdo Ruotolo," Evaluation of the non-linear dynamic response to harmonic excitation of a beam with several breathing cracks. ", Journal of Sound and Vibration (2000) 235(5), 749-762.

[15] K. R. Collins, P. H. Plaut and P. H. Wauer " Free and forced longitudinal vibrations of a cantilevered bar with a crack.", (1992) Journal of vibration and Acoustics 114, 171-177.

[16] Nobuo Sobue , Minori Fujita , Atsuko Nakano, Tomohiro Suzuki." Identification of defect position in a wooden beam from the power spectrum of longitudinal vibration". Journal of Wood Science (2010) 56:112-117.

[17] W. M. Lee - J. T. Chen. " Null-field integral equation approach for free vibration analysis of circular plates with multiple circular holes". Computational Mechanics (2008) 42:733-747.

[18] Nikolakopoulos P.G., Katsareas D.E., Papadopoulos C.A. "Crack identification in frame structures". Computers and Structures (1997);64(1-4):389-406.

[19] Papadrakakis M, editor. "Crack Identification in Structures. Computational Structural Engineering For Practice"; (1994) Aug; : Civil-Comp Press; 1994.

[20]- Singh, Sadhu. Mechanical Vibrations \& Noise Control. Khanna Publishers $1^{\text {st }}$ Reprint (2006).

[21] Jiawei Xiang, Yongteng Zhong, Xuefeng Chen, Zhengjia He, "Crack detection in a shaft by combination of wavelet-based elements and genetic algorithm.", International Journal of Solids and Structures, 45, (2008), pp.4782-4795.

[22] William T. Thomson, "Theory of Vibration With Application.", $2^{\text {nd }}$ Edition, $3^{\text {rd }}$ impression (1986), George Allen \& Unwin ltd. 